\title{
Solvothermal growth of single-crystal CdS nanowires
}

\author{
M A MAHDI ${ }^{1,2, *}, \mathbf{J}$ J HASSAN ${ }^{1,2}, \mathbf{S} \mathbf{J}$ KASIM ${ }^{2}, \mathbf{S} \mathbf{S ~ N G}^{1}$ and Z HASSAN ${ }^{1}$ \\ ${ }^{1}$ Nano-Optoelectronics Research and Technology Laboratory (N.O.R.), School of Physics, Universiti Sains Malaysia, \\ 11800 Penang, Malaysia \\ ${ }^{2}$ Physics Department, College of Science, Basrah University, Basrah 61004, Iraq
}

MS received 29 September 2012; revised 20 November 2012

\begin{abstract}
Cadmium sulfide (CdS) nanowires (NWs) were prepared by the solvothermal method using ethylenediamine as a solvent. Two sets of $\mathrm{CdS}$ NWs were synthesized at 160 and $200{ }^{\circ} \mathrm{C}$ for various reaction durations $(3.5,7$ and $24 \mathrm{~h}$ ). Scanning/tunneling electron microscopy was used to examine the surface morphology of the grown NWs. Their dimensions are found to depend on the reaction temperature and duration. The CdS NWs grown at $200{ }^{\circ} \mathrm{C}$ for all durations are longer than those prepared at $160{ }^{\circ} \mathrm{C}$, with diameters ranging from 15 to $40 \mathrm{~nm}$. A threearmed structure is exhibited by all the samples. The grown CdS NWs display a hexagonal wurtzite phase and grows along the $\langle 001\rangle$ direction. The optical absorption of the grown NWs shows a sharp absorption edge with a blueshift, which indicates an expansion of the optical band gap. All prepared samples show two emission peaks in their photoluminescence spectra. The emission peak location depends on the reaction temperature and duration. The CdS NWs prepared at $160{ }^{\circ} \mathrm{C}$ show a sharp band-band emission compared with those prepared at $200{ }^{\circ} \mathrm{C}$. Raman analysis indicates that the optical properties of the grown NWs are enhanced with increased temperature and reaction duration.
\end{abstract}

Keywords. Cadmium sulfide; nanowire; solvothermal method.

\section{Introduction}

Considerable interest is focused on the synthesis of nanocrystalline materials because of their unique physical and chemical properties that distinguish them from bulk-phase materials. The particle size and shape of materials significantly affect their properties. Thus, control of the size and morphology of nanocrystalline materials can lead to the discovery of new physical and chemical properties (Wang et al 2011). One-dimensional (1D) semiconductors such as nanowires (NWs), nanorods and nanoribbons have several unique advantages, including high crystallinity, selfassembly, high surface-to-volume ratio, quantum confinement effects and slow electron-hole recombination (Choi et al 2010; Mahdi et al 2012a; Rai et al 2012). The ability to grow $1 \mathrm{D}$, single-crystal and nanostructured semiconductors has led to the fabrication of functional nanoscale devices ( $\mathrm{Li}$ et al 2005, 2010; Yingkai et al 2006; Xi et al 2010; Mahdi et al 2012a). Among group II-VI semiconductor materials, cadmium sulfide $(\mathrm{CdS}$; direct band gap $=2.42 \mathrm{eV}$ ), is considered to be an excellent material for various optoelectronic applications within the visible range of the electromagnetic spectrum (Yan et al 2009; Mahdi et al 2012b). 1D CdS has been prepared using

\footnotetext{
*Author for correspondence (mazinauny74@yahoo.com)
}

various methods, such as D.C. electrochemical techniques (Mondal et al 2007a), thermal evaporation (Kar and Chaudhuri 2006), chemical vapour deposition (Ma et al 2007) and hydro/solvothermal methods (Qingqing et al 2005; Xu et al 2005; Nirmala Jothi et al 2011). Solvothermal synthesis is widely used to prepare semiconductor NWs, particularly CdS. This synthesis can enable the control wire morphology and dimensions via reaction variables such as solvent type, temperature and duration (Datta et al 2009). The solvo/hydrothermal method is also simple, easy to scale up, low-energy consuming and cost-effective (Yan et al 2009; Chen and Wu 2011). In the solvothermal method, preparation parameters such as reaction temperature, duration and solvent type have crucial functions in determining the nature of the product as well as its physical properties. The solvothermal method can produce high-purity nanocrystalline materials with a high degree of crystallinity compared with other solution-based methods (Dalvand et al 2011). In the present work, CdS NWs were grown by the solvothermal method. The effects of the reaction temperature and duration on NW morphology, crystalline structure and optical properties were investigated.

\section{Materials and methods}

Cadmium nitrate $\left[\mathrm{Cd}\left(\mathrm{NO}_{3}\right)_{2} \cdot 4 \mathrm{H}_{2} \mathrm{O}\right]$ and sulfur (S) powder were used as $\mathrm{Cd}^{2+}$ and $\mathrm{S}^{2-}$ ion sources, respectively. Approximately $0.22 \mathrm{~g}$ of $\left[\mathrm{Cd}\left(\mathrm{NO}_{3}\right)_{2} \cdot 4 \mathrm{H}_{2} \mathrm{O}\right]$ and $0.066 \mathrm{~g}$ of $\mathrm{S}$ 
powder were dissolved in $50 \mathrm{ml}$ of ethylenediamine (en) and stirred for $10 \mathrm{~min}$. The solution was poured into a $100 \mathrm{ml}$ teflon-lined stainless steel autoclave filled with en to $60 \%$ of its total volume capacity. The autoclave was sealed and subsequently loaded into an oven. Two sets of samples were prepared at different reaction temperatures and durations. The first set was prepared at $160{ }^{\circ} \mathrm{C}$ for $3 \cdot 5,7$ and $24 \mathrm{~h}$, whereas the other set was grown at $200{ }^{\circ} \mathrm{C}$ for the same durations. After removing the autoclave from the oven and cooling naturally, the resulting yellow precipitates were filtered, washed several times with absolute ethanol as well as distilled water and then air dried at $60{ }^{\circ} \mathrm{C}$ for $2 \mathrm{~h}$. A field-emission scanning electron microscopy (FESEM) system (FEI Nova NanoSEM 450) was used to determine the morphology of the products. The microstructures were investigated by a transmission electron microscopy (TEM) system (Libra 120-Carl Zeiss). The crystalline structure of the prepared $\mathrm{CdS}$ nanostructures was investigated by X-ray diffraction (XRD) using a PANalytical X'Pert PRO MRD PW3040 instrument with $\mathrm{CuK} \alpha$ radiation. Optical properties such as absorption, photoluminescence (PL) and Raman spectra were measured using a Shimadzu UV-Vis spectrophotometer (UV-1800) and Horiba Jobin Yvon H 800 UV equipment.
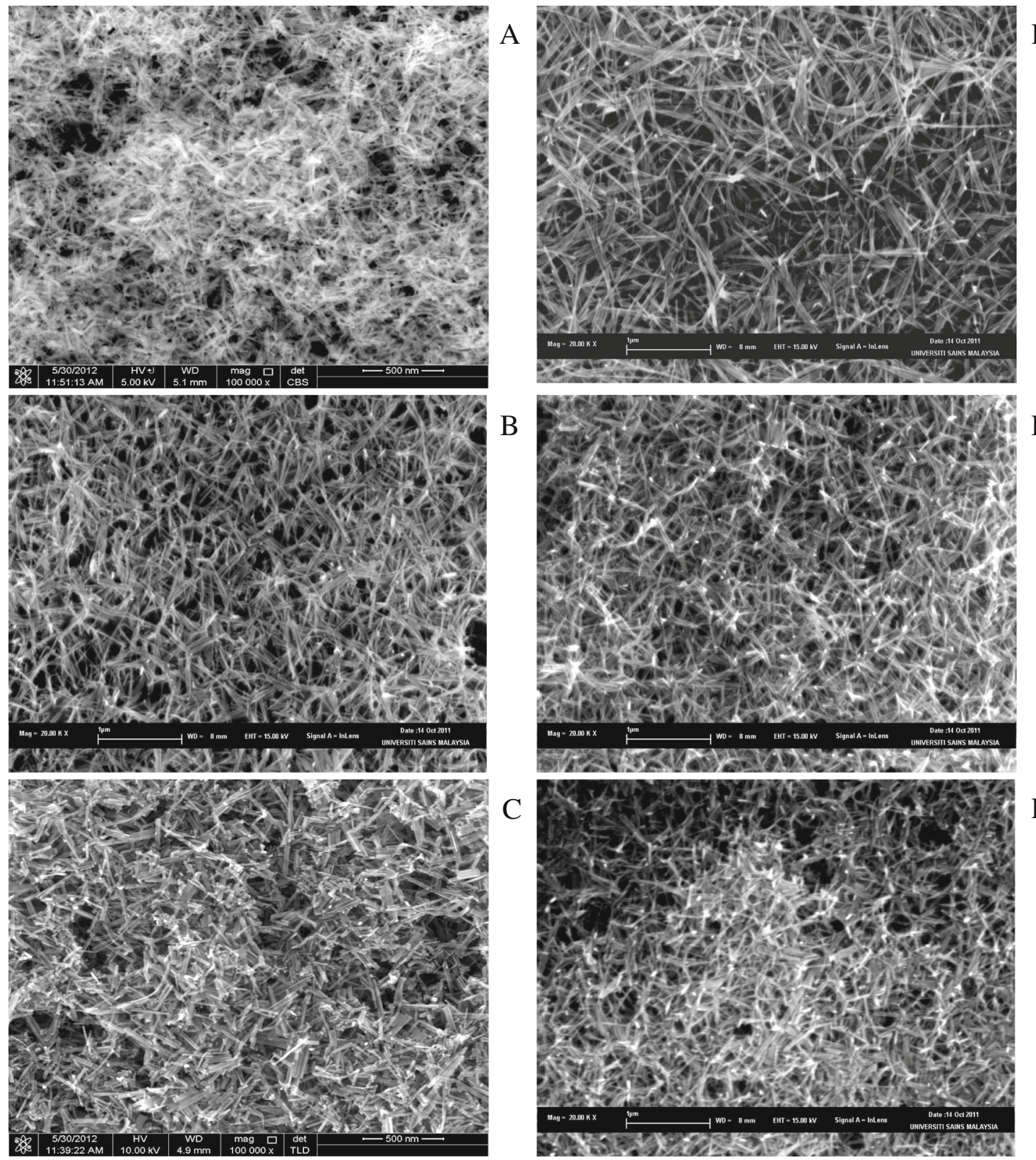

\section{$\mathrm{D}$}

B

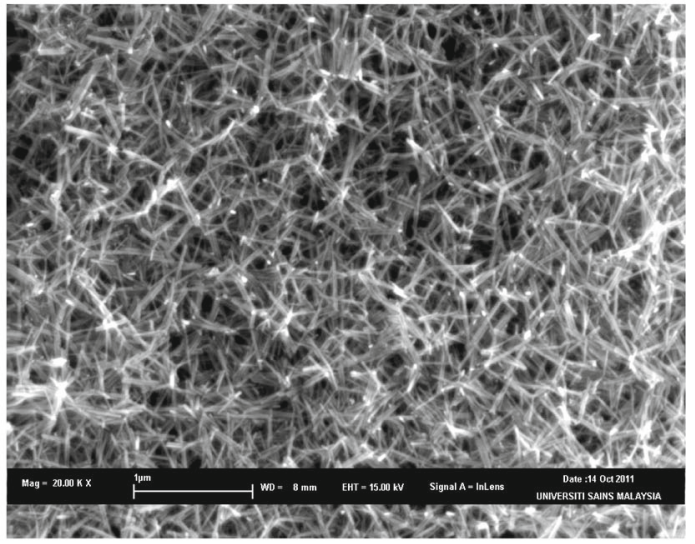

$\mathrm{C}$

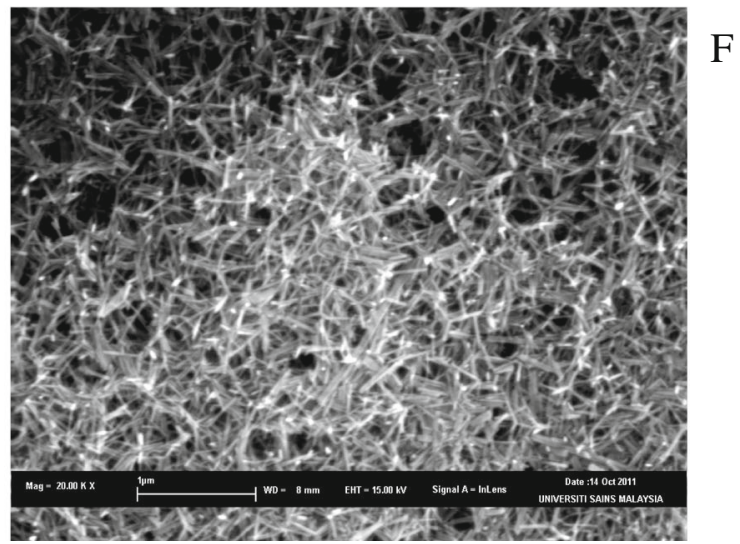

Figure 1. FESEM images of CdS nanowires (A, B and C) prepared at $160^{\circ} \mathrm{C},(\mathrm{D}, \mathrm{E}$ and $\mathrm{F})$ at $200{ }^{\circ} \mathrm{C}$ for $3 \cdot 5,7 \cdot 0$ and $24 \mathrm{~h}$. 


\section{Results and discussion}

\subsection{Surface morphology}

Figure 1 shows the FESEM images of the CdS NWs grown at 160 and $200{ }^{\circ} \mathrm{C}$ for various reaction durations. Figure 1 (A-C) shows the CdS NWs prepared at $160{ }^{\circ} \mathrm{C}$ for $3.5,7$ and $24 \mathrm{~h}$, respectively; figure 1(D-F) displays the CdS NWs prepared at $200{ }^{\circ} \mathrm{C}$ for the same durations. The results show that the dimensions of the grown CdS NWs depend on the reaction temperature and duration. The grown NWs exhibit uniform shapes and similar diameters, as clearly shown by the TEM images (figure 2). The TEM image of the sample prepared at $160{ }^{\circ} \mathrm{C}$ for $3.5 \mathrm{~h}$ contains a number of nanoparticles in addition to the NW structure. In the solvothermal method, two mechanisms are involved in the formation of the 1D structure. $\mathrm{Cd}^{2+}$ ions interact with the lone pair of electrons of the en nitrogen atoms to form a Cd-en $\left[\mathrm{Cd}(\mathrm{en})_{2}\right]^{2+}$ complex. $\mathrm{S}^{2-}$ ions are then slowly released into the solution, consequently, increasing the temperature and resulting in the combination of the $\mathrm{Cd}^{2+}$ and $\mathrm{S}^{2-}$ ions to form a two-dimensional (2D), CdS-0.5en complex structure, as shown in the following reaction:

$$
\mathrm{Cd}^{2+}+2 \mathrm{en} \rightarrow \mathrm{Cd}(\mathrm{en})_{2}+\mathrm{S}^{2-} \rightarrow \mathrm{CdS}+2 \mathrm{en} .
$$

This complex has an organic-inorganic lamellar structure with inorganic $\mathrm{CdS}$ layers separated by organic en spacers (Kar et al 2008). The 2D complex structure becomes unstable with increased temperature until around $120^{\circ} \mathrm{C}$; thus, the

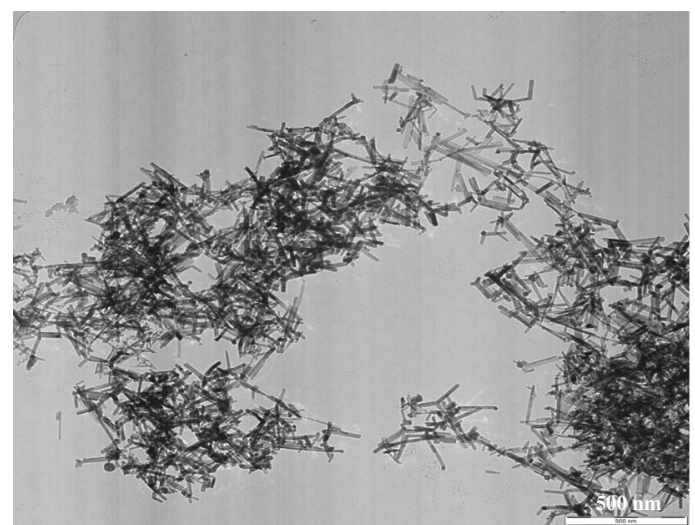

A

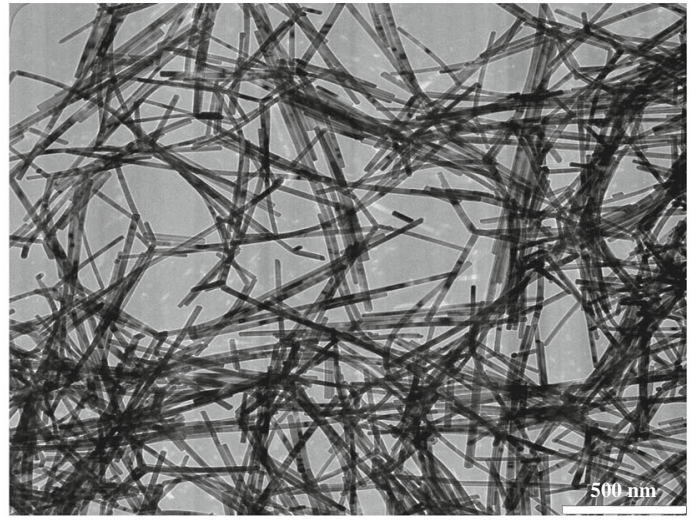

$\mathrm{D}$
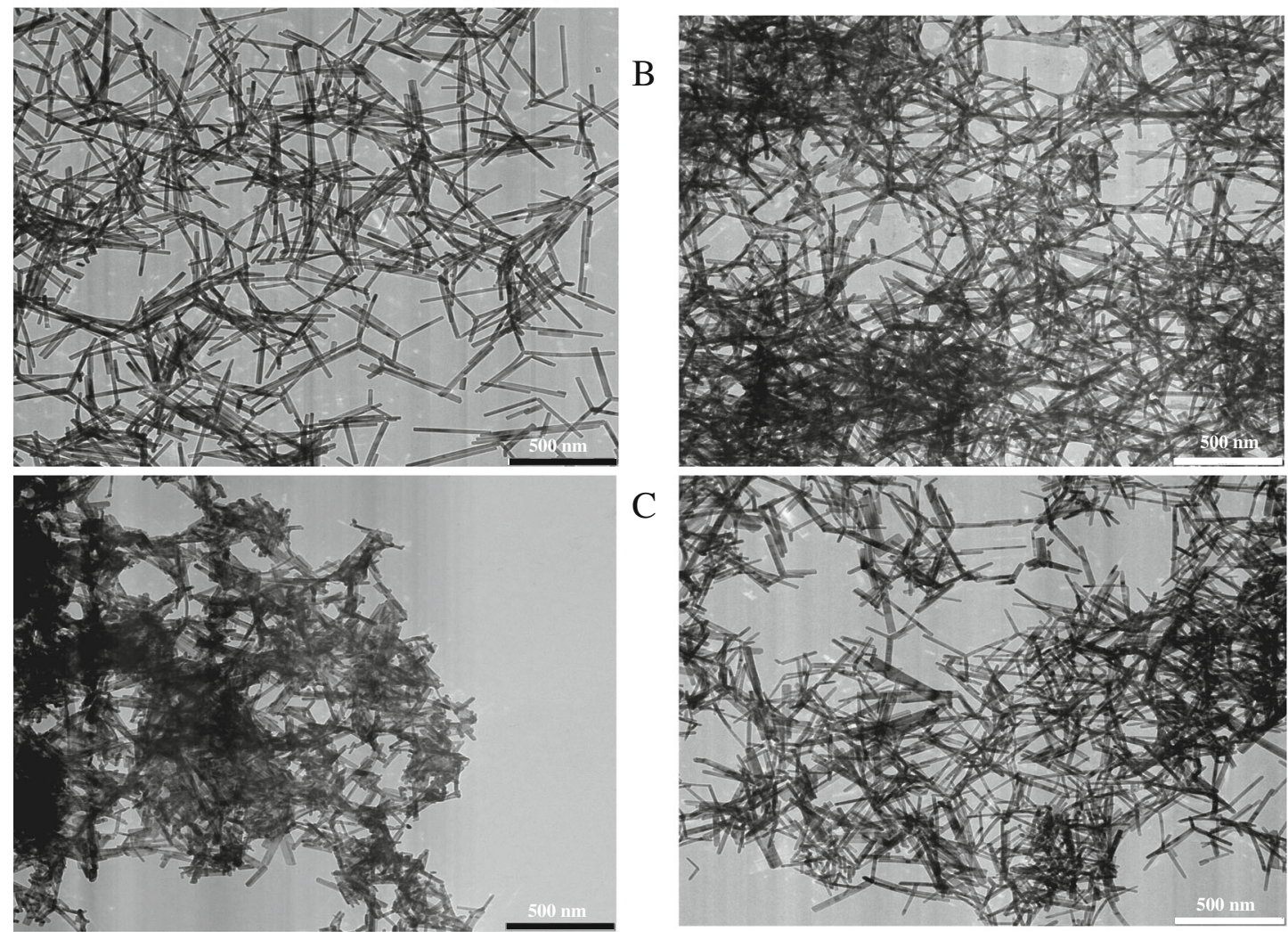

C

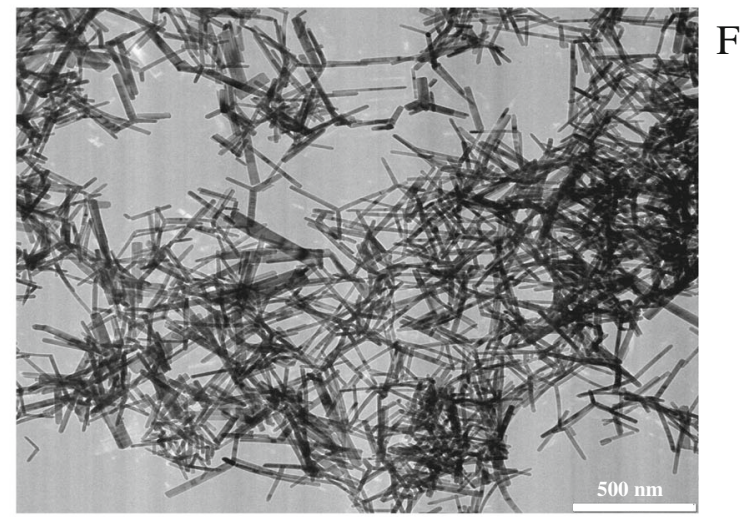

Figure 2. TEM images of $\mathrm{CdS}$ nanowires (A, B and C) prepared at $160{ }^{\circ} \mathrm{C},(\mathrm{D}, \mathrm{E}$ and $\mathrm{F})$ at $200{ }^{\circ} \mathrm{C}$ for $3 \cdot 5,7 \cdot 0$ and $24 \mathrm{~h}$. 
complex fragments into a 1D needle-like structure to achieve stability. The needle-like structure then grows to form NWs due to the high surface energy. Mahdi et al (2012c) grown $\mathrm{CdS}$ nanostructures by solvothermal and they noted that the CdS prepared at 100 and $120{ }^{\circ} \mathrm{C}$ grew into nanosheets, and those prepared at 160 and $200{ }^{\circ} \mathrm{C}$ developed a nanowire structure. On the other hand, a number of uncoupled $\mathrm{Cd}^{2+}$ ions directly react with $\mathrm{S}^{2-}$ ions to form CdS nanoparticles. These nanoparticles also serve as nuclei for the growth of CdS NWs in solution. A three-armed nanorod structure is also shown in the TEM images (figure 3). This three-armed structure frequently appears in all the samples prepared at 160 and $200{ }^{\circ} \mathrm{C}$. The $1 \mathrm{D} \mathrm{CdS}$ structure grows into nanorods, as clearly shown by the hexagonal shape in figure 3 . The three-armed structure is due to the presence of CdS nanoparticles in the solution, which acts as nuclei for the growth of CdS nanorods. Chen et al (2002) grew CdS nanorods by solvothermal synthesis using CdS nanoparticles as seeds to nucleate CdS nanorods, and they obtained tetrapod structures. The NW diameter distribution analysis shows that the diameters of CdS NWs grown at $160{ }^{\circ} \mathrm{C}$ for 3.5 and $24 \mathrm{~h}$ range from 10 to $30 \mathrm{~nm}$, whereas those of CdS nanorods prepared for $7 \mathrm{~h}$ range from 15 to $40 \mathrm{~nm}$ (figure 4). This difference in diameter may be due to the higher concentration of the three-armed structure in the sample prepared for $7 \mathrm{~h}$ than the other samples. Interestingly, the NWs shorten with increased reaction duration to $24 \mathrm{~h}$ and some CdS nanosheets appear. The longer duration may have caused the wire to break into shorter pieces. The appearance of a number of $\mathrm{CdS}$ nanosheets may have been due to the growth of sheets that do not break into the needle structure. However, the reason for the absence of nanosheet structures in the sample prepared for $7 \mathrm{~h}$ is unclear. Figure 2(D-F) show that the CdS NWs grown at $200{ }^{\circ} \mathrm{C}$ for $3 \cdot 5,7$ and $24 \mathrm{~h}$, respectively, are longer than those prepared at $160{ }^{\circ} \mathrm{C}$. The wire diameters of these NWs range from 15 to $35 \mathrm{~nm}$, as indicated by the wire diameter distribution results in figure 4 .

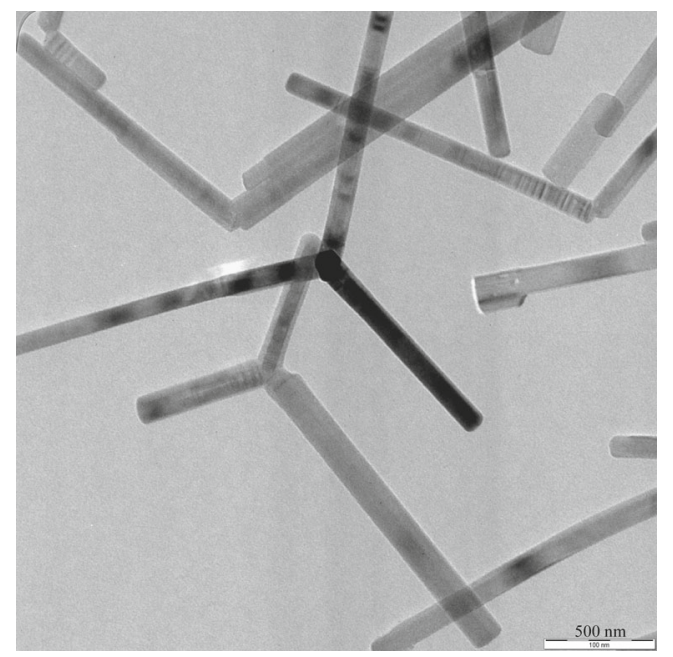

Figure 3. TEM image of three-arm CdS nanorod prepared at $160{ }^{\circ} \mathrm{C}$ for $7 \cdot 0 \mathrm{~h}$.
Jang et al (2007) prepared 1D CdS by the solvothermal method at different reaction temperatures and durations. They noted that with increased duration, CdS NWs grown at $160{ }^{\circ} \mathrm{C}$ increase in length but not in diameter. Moreover, Datta et al (2009) studied the reaction temperature (150$250{ }^{\circ} \mathrm{C}$ ) and duration $(5-48 \mathrm{~h})$ effect on the morphology, crystalinity and the optical properties of CdS NWs prepared via sovothermal on $\mathrm{Cd}$ foil substrate. They noted that the wires were grown vertically on the substrate and the diameter average was $200-400 \mathrm{~nm}$. The elemental ratios $(\mathrm{Cd} / \mathrm{S})$ of all grown CdS NWs range from $1 \cdot 10$ to $1 \cdot 12$, as determined by energy dispersive $\mathrm{X}$-ray measurements.

\subsection{Crystalline structure}

The crystalline structure of the solvothermally prepared CdS NWs was determined by XRD analysis, and the results are shown in figure 5(A and B). Compared with a standard XRD database (PDF-4, 00-001-0780), the grown CdS NWs exhibit hexagonal wurtzite structures belonging to the $C_{6 v}^{4} \mathrm{CdS}$ space group. The preferred orientation of the grown NWs can be predicted from the following formula (Phuruangrat et al 2010):

$$
P_{(\mathrm{hkl})}=\frac{I_{(\mathrm{hkl})} \sum I_{(\mathrm{hkl})}^{\prime}}{I_{(\mathrm{hkl})}^{\prime} \sum I_{(\mathrm{hkl})}}
$$

where $I_{(\mathrm{hkl})}$ and $I_{(\mathrm{hkl})}^{\prime}$ are the integrated intensities of the experimental and random (simulated) XRD diffractions, respectively. For a random orientation, $P$ equals one. For a particular $(h k l)$ plane with a preferred orientation, $P$ is greater than one. The calculated $P_{\mathrm{hkl}}$ values of the grown CdS NWs prepared at 160 and $200{ }^{\circ} \mathrm{C}$ are listed in table 1 . The preferred orientation of the NWs prepared at $160{ }^{\circ} \mathrm{C}$ for $3.5 \mathrm{~h}$ is along the $\langle 001\rangle$ direction. This preferred orientation changes to the $\langle 100\rangle$ direction with increased reaction duration to 7 and $24 \mathrm{~h}$. The XRD patterns of the CdS NWs prepared at $200{ }^{\circ} \mathrm{C}$ indicate that the samples are more crystalline than those prepared at $160{ }^{\circ} \mathrm{C}$ (figure 5(B)). The preferred orientation of the CdS NWs grown at $200{ }^{\circ} \mathrm{C}$ also depends on the reaction duration. The preferred orientation of the CdS NWs prepared for $3.5 \mathrm{~h}$ is along the $\langle 110\rangle$ direction. Increasing the reaction duration to 7 and $24 \mathrm{~h}$ changes this orientation to the $\langle 100\rangle$ direction. Dalvand and Mohammadi (2011) studied the effect of preparation parameters on the crystalline structure, morphology and optical properties of solvothermally grown CdS NWs using en as a solvent as well as $\mathrm{Cd}(\mathrm{Ac})_{2} \cdot 2 \mathrm{H}_{2} \mathrm{O}$ and $\mathrm{S}$ powder as ion sources. They concluded that the preferred orientation of the NWs prepared at $160{ }^{\circ} \mathrm{C}$ for $12 \mathrm{~h}$ was along $\langle 110\rangle$. This orientation changes to the $\langle 100\rangle$ direction with increased reaction temperature to $200^{\circ} \mathrm{C}$. They also noted that the preferred orientation changes from $\langle 110\rangle$ to $\langle 100\rangle$ with increased reaction duration from 12 to $24 \mathrm{~h}$. Datta et al (2009) noted that the CdS nanowires grown along (001) direction and the wires became more crystalline when the temperature of the preparation increased from 150 to $250{ }^{\circ} \mathrm{C}$. Surface atoms have higher energies than interior atoms and 

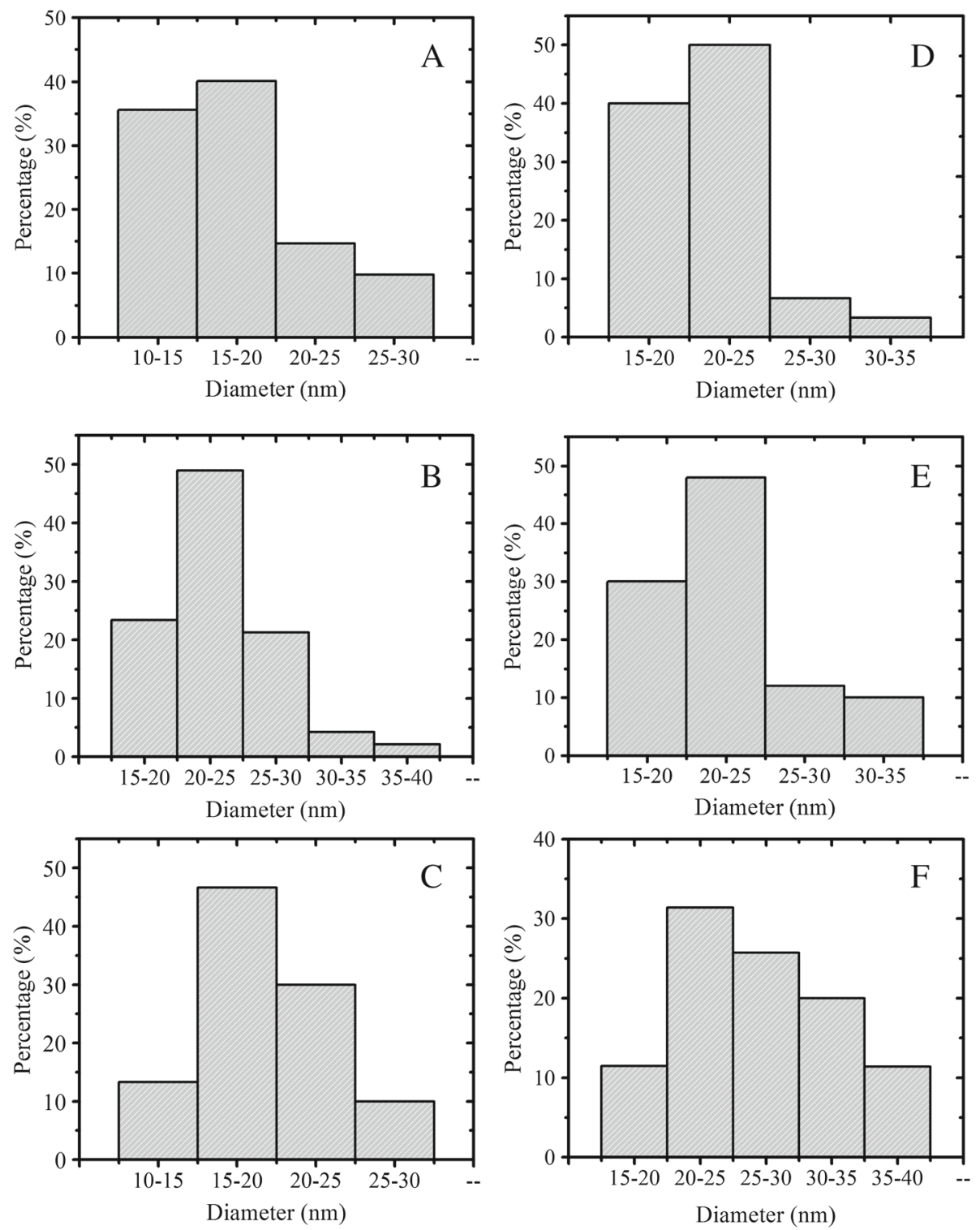

Figure 4. Diameter distribution of CdS nanowires (A, B and C) prepared at $160^{\circ} \mathrm{C},(\mathrm{D}, \mathrm{E}$ and F) at $200{ }^{\circ} \mathrm{C}$ for $3.5,7.0$ and $24 \mathrm{~h}$.

thus significantly affect the growth direction. For the hexagonal structure, the atomic density is higher on the (001) surface than on the (100) and (110) surfaces. Therefore, atoms on the (002) face have significantly lower excess energy than atoms on other faces (Phuruangrat et al 2009). The preferred orientation in all prepared CdS NWs is along the $\langle 100\rangle$ or $\langle 110\rangle$ direction, which makes a $90^{\circ}$ angle with $\langle 001\rangle$. Hence, the growth direction of the grown CdS NWs is along $\langle 001\rangle$. The (002) peak intensity is higher than those of the (100) and (101) planes of the CdS NWs grown at $160{ }^{\circ} \mathrm{C}$ for $3.5 \mathrm{~h}$, which may be due to the lower aspect ratio (Zhou et al 2011). Growth along the $c$-axis of the NW wurtzite structure benefits optoelectronic and electro-optic applications due to the polarized light emission along the $c$-axis of the wire (Thupakula et al 2012). Growth along the $\langle 001\rangle$ direction indicates that the grown NWs are bipolar because of the noncentrosymmetric charge distribution in the wurtzite crystal along the $c$-axis (Thupakula et al 2012). The lattice constants $\mathrm{a}$ and $\mathrm{c}$ for the hexagonal structure are calculated using the following equation (Nien et al 2008):

$$
\frac{1}{d_{\mathrm{hkl}}^{2}}=\frac{4}{3}\left(\frac{h^{2}+h k+k^{2}}{a^{2}}\right)+\frac{l^{2}}{c^{2}}
$$

where $d_{\mathrm{hkl}}$ is the interplanar spacing of the atomic planes; and $h, k$ and $l$ are the Miller indices.

The calculated lattice parameter values of the prepared samples are almost identical to standard data (table 1). The particle size, $P_{\mathrm{S}}$ can be calculated from the XRD peak 


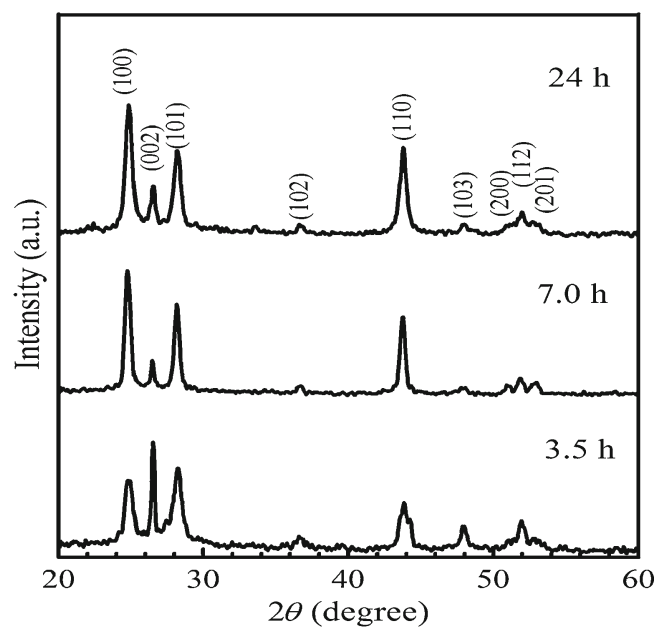

(A)

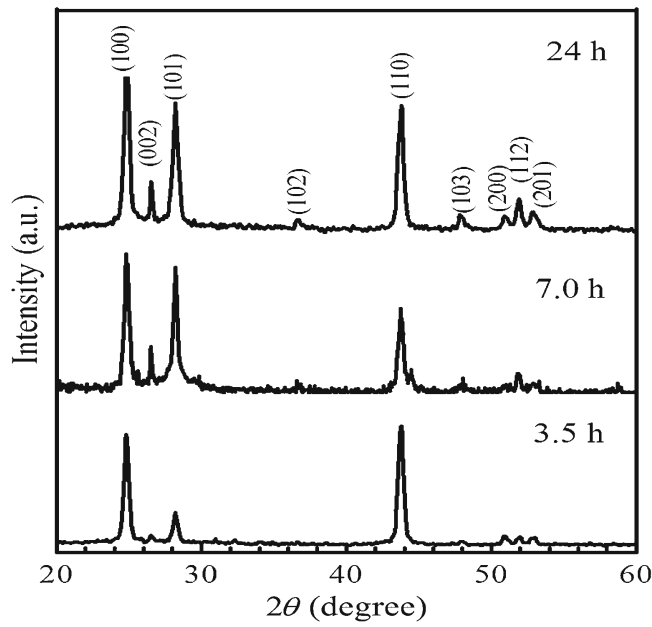

(B)

Figure 5. XRD patterns of $\mathrm{CdS}$ nanowires prepared (A) at $160{ }^{\circ} \mathrm{C}$ and (B) $200{ }^{\circ} \mathrm{C}$ for various times.

broadening using the Debye-Scherer equation (Thupakula et al 2012):

$$
P_{\mathrm{S}}=\frac{K \times \lambda}{\beta \cos \theta},
$$

where $K$ is a shape factor, $\lambda$ the $\mathrm{X}$-ray radiation wavelength $(\sim 0.15 \mathrm{~nm}), \beta$ the full-width at half-maximum (FWHM) of the XRD diffraction peak and $\theta$ the half of the diffraction angle. The CdS NW growth direction is along $\langle 001\rangle$. Thus, the FWHM of the (002) plane is used to calculate $P_{S}$. The diameters $\left(R_{\mathrm{w}}\right)$ of the grown CdS NWs are estimated using $P_{\mathrm{S}}=2 R_{\mathrm{w}}$. The estimated $R_{\mathrm{w}}$ values are listed in table 1 . The calculated $R_{\mathrm{W}}$ found close to the dominated diameter of the grown CdS NWs that estimated by TEM images. Thus, XRD can be used as a method to estimate the diameter of the grown wires.

\subsection{Optical properties}

3.3a Optical absorption: Optical studies were performed by measuring the absorption of the prepared CdS NWs within the 300-900 nm wavelength range. Figure 6 shows the UV-Vis absorption of the CdS NWs prepared at 160 and $200{ }^{\circ} \mathrm{C}$ for different durations. The absorption edge of $\mathrm{CdS}$ NWs grown at $160{ }^{\circ} \mathrm{C}$ for 3.5 and $7 \mathrm{~h}$ is observed at around $480 \mathrm{~nm}$; this peak shifted to $\sim 485 \mathrm{~nm}$ for the NWs prepared for $24 \mathrm{~h}$ (figure 6A). Thus, the optical band gap for the NWs prepared for 3.5 and $7.0 \mathrm{~h}$ is $2.58 \mathrm{eV}$, and that for the NWs prepared for $24 \mathrm{~h}$ is $2.55 \mathrm{eV}$. The absorption band peaks for the NWs grown at $200{ }^{\circ} \mathrm{C}$ for all durations peak at $\sim 485 \mathrm{~nm}$ (figure 6B). The obtained optical band gap values are higher than the bulk value $(2.42 \mathrm{eV}$ and $\sim 515 \mathrm{~nm}$ ) (Mahdi et al 2012b). The sharp absorption peak of the CdS NWs can be attributed to their size uniformity and high crystallinity (Jang et al 2007; Yan et al 2009). Using the solvothermal method, Yan et al (2009) prepared CdS NWs with diameters ranging from 23 to $37 \mathrm{~nm}$ and an optical energy gap of $2.56 \mathrm{eV}$.

3.3b Photoluminescence spectra analysis: The roomtemperature PL emission spectra of the CdS NWs prepared at 160 and $200{ }^{\circ} \mathrm{C}$ are shown in figure 7 . The CdS NWs prepared at $160{ }^{\circ} \mathrm{C}$ for 3.5 and $7 \mathrm{~h}$ show a sharp PL emission band at around $496 \mathrm{~nm}(2.5 \mathrm{eV})$, which correspond to a typical band-band transition. The observed PL band at $496 \mathrm{~nm}$ is blue shifted from bulk CdS (500-700 nm). However, the emission bands comes either from band edge or recombination of surface states energy level (Sadhu et al 2008). The PL emission of the NWs prepared for $24 \mathrm{~h}$ redshifts to $519 \mathrm{~nm}$ $(2.39 \mathrm{eV})$, as shown in figure 7(A). A broad yellow emission is observed at $668 \mathrm{~nm}(1.85 \mathrm{eV})$ for the NWs prepared for 3.5 and $7 \mathrm{~h}$; this emission peaks at $\sim 690 \mathrm{~nm}(1.8 \mathrm{eV})$ for the NWs grown for $24 \mathrm{~h}$. Excess Cd in CdS can lead to the formation of an acceptor level within the CdS optical band gap. Thus, the defect band is attributed to the transition of Cd-interstitial donors to the valence band (Tsai et al 1996). Ahmad-Bitar (2000) attributed the appearance of the defect emission band to recombination via surface localized states, the transition from $I_{\mathrm{Cd}}$ to the valance band, and the transition from the interstitial $\mathrm{Cd}-\mathrm{Cd}$ vacancy complex that acts as a donor to an accepter level. The shift in the defect band position may also be related to the effect of the concentration of the defect levels. Interestingly, the CdS NWs prepared at $200{ }^{\circ} \mathrm{C}$ for all durations show a sharp PL emission band at $512 \mathrm{~nm}$ and another broad emission band at $690 \mathrm{~nm}$. The PL intensities of the CdS NWs prepared for $3.5 \mathrm{~h}$ at 160 and $200{ }^{\circ} \mathrm{C}$ are the highest among all the samples. Table 2 summarizes the optical properties of the CdS NWs prepared at 160 and $200{ }^{\circ} \mathrm{C}$. However, Datta and his workers (2009) noted that the solvothermally grown CdS NWs showed a distinct blue shift of the PL peak position which centered at $\sim 530 \mathrm{~nm}$ from low temperature $\left(180{ }^{\circ} \mathrm{C}\right)$ to the higher temperature $\left(250{ }^{\circ} \mathrm{C}\right)$ prepared samples.

3.3c Raman spectra analysis: Figure 8(A and B) shows the room-temperature Raman spectra of all prepared $\mathrm{CdS}$ NWs excited by $515 \mathrm{~nm} \mathrm{Ar}^{+}$laser light. The two observed 
Table 1. Crystalline parameters of prepared CdS NWs prepared at $160{ }^{\circ} \mathrm{C}$ and $200{ }^{\circ} \mathrm{C}$ for $3 \cdot 5,7 \cdot 0$ and $24 \mathrm{~h}$.

\begin{tabular}{lcccccc}
\hline $\begin{array}{l}\text { Preparation } \\
\text { temperature }\left({ }^{\circ} \mathrm{C}\right)\end{array}$ & $\begin{array}{c}\text { Time } \\
(\mathrm{h})\end{array}$ & $\begin{array}{c}\text { Orientation } \\
\text { face }\end{array}$ & $P_{\mathrm{hkl}}$ & $a(\AA)$ & $c(\AA)$ & $\begin{array}{c}R_{\mathrm{w}} \\
(\mathrm{nm})\end{array}$ \\
\hline 160 & $3 \cdot 5$ & $(002)$ & $2 \cdot 51$ & $4 \cdot 14$ & $6 \cdot 71$ & 20 \\
$=$ & $7 \cdot 0$ & $(100)$ & 1.55 & $4 \cdot 15$ & $6 \cdot 73$ & 21 \\
$=$ & 24 & $(100)$ & 1.42 & $4 \cdot 11$ & $6 \cdot 71$ & 18 \\
200 & $3 \cdot 5$ & $(110)$ & $2 \cdot 42$ & $4 \cdot 13$ & $6 \cdot 72$ & 17 \\
$=$ & $7 \cdot 0$ & $(100)$ & 1.29 & $4 \cdot 13$ & $6 \cdot 72$ & 20 \\
$=$ & 24 & $(100)$ & 1.41 & 4.13 & $6 \cdot 71$ & 23 \\
\hline
\end{tabular}

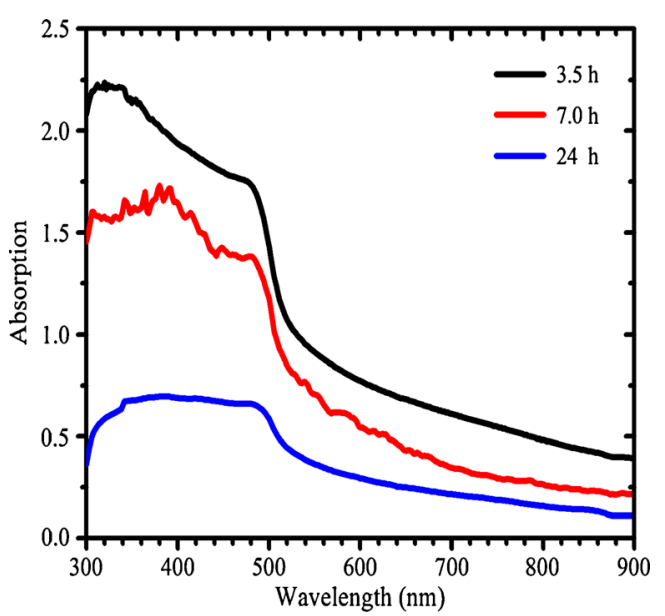

(A)

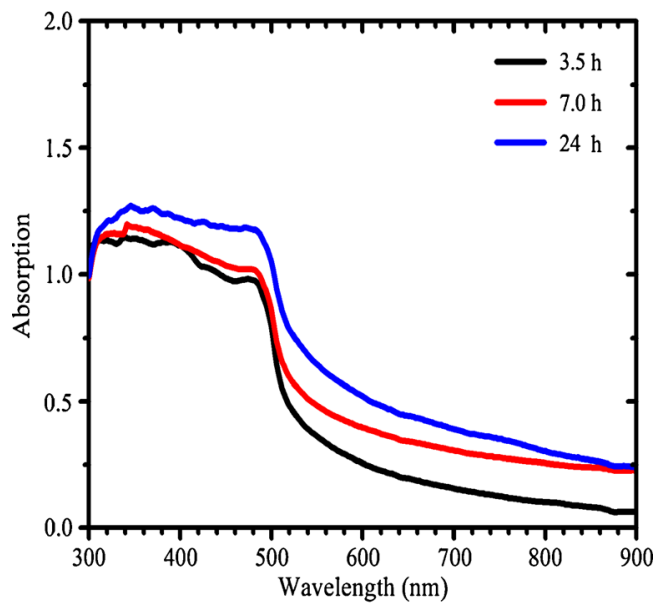

(B)

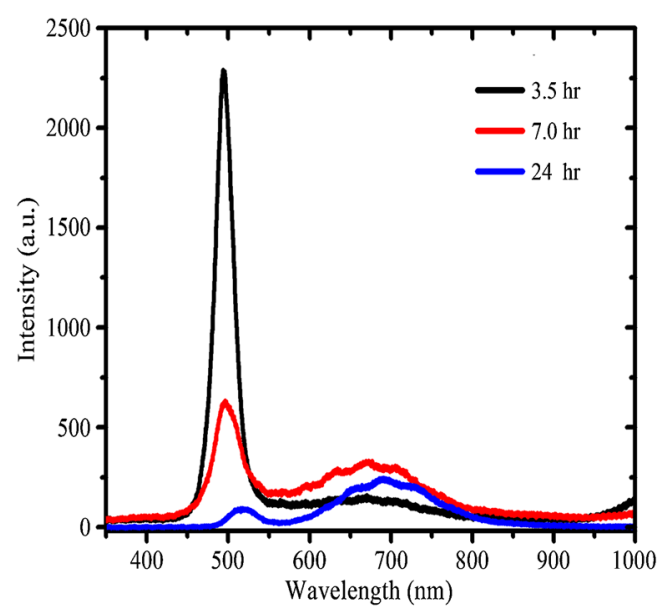

(A)

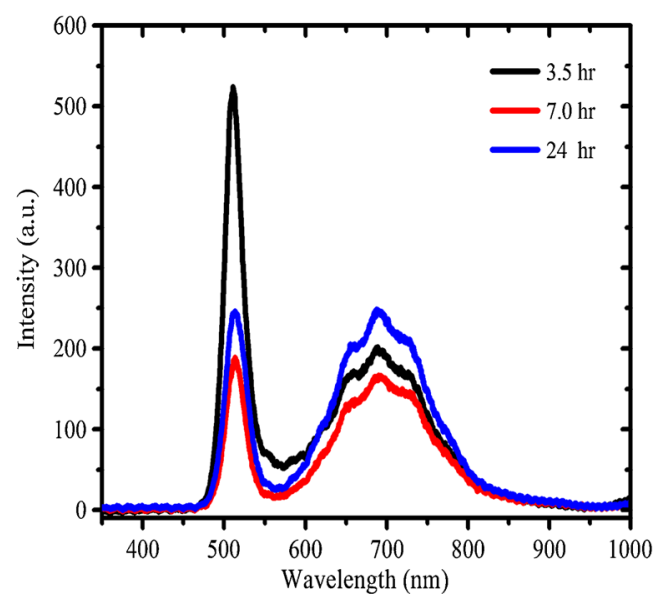

(B)
Figure 6. Optical absorption of CdS nanowires prepared (A) at $160{ }^{\circ} \mathrm{C}$ and (B) at $200{ }^{\circ} \mathrm{C}$ for various times.

peaks in the Raman spectra correspond to the first-order (1LO) and second-order (2LO) longitudinal optical phonon modes of $\mathrm{CdS}$, which are polarized in the $x-z$ face and strongly coupled to the exciton along the $c$-axis (Arguello et al 1969; Wang et al 2002; Pan et al 2005; Mondal et al 2007b). For all the samples prepared at $160{ }^{\circ} \mathrm{C}$, the $1 \mathrm{LO}$ peak is located at $298 \mathrm{~cm}^{-1}$. The $2 \mathrm{LO}$ peak of the samples prepared for 3.5 and $7 \mathrm{~h}$ appear at $600 \mathrm{~cm}^{-1}$ and redshifts to $590 \mathrm{~cm}^{-1}$ for the sample prepared at $24 \mathrm{~h}$ (figure $8(\mathrm{~A})$ ). The
Figure 7. Photoluminance spectra of CdS nanowires prepared (A) at $160{ }^{\circ} \mathrm{C}$ and (B) at $200{ }^{\circ} \mathrm{C}$ for various times.

Raman spectra show that the 1LO and 2LO peaks of all the samples prepared at $200{ }^{\circ} \mathrm{C}$ are located at 299 and $600 \mathrm{~cm}^{-1}$, respectively. For bulk CdS, the fundamental 1LO and overtone $2 \mathrm{LO}$ modes are located at 305 and $605 \mathrm{~cm}^{-1}$, respectively (Mahdi et al 2012b). Thus, the redshift in the positions of the 1LO and 2LO modes in all prepared CdS NWs samples occurs because of the phonon confinement effect (Owens and Poole 2008). The exciton-phonon coupling strength in semiconductors can be determined from 
Table 2. Optical results of CdS NWs prepared at $160{ }^{\circ} \mathrm{C}$ and $200{ }^{\circ} \mathrm{C}$ for $3 \cdot 5,7 \cdot 0$ and $24 \mathrm{~h}$.

\begin{tabular}{lcccccc}
\hline $\begin{array}{l}\text { Preparation } \\
\text { temperature }\left({ }^{\circ} \mathrm{C}\right)\end{array}$ & $\begin{array}{c}\text { Preparation } \\
\text { time }(\mathrm{h})\end{array}$ & $\begin{array}{c}\text { Absorption } \\
\text { peak }(\mathrm{nm})\end{array}$ & $\begin{array}{c}\text { PL peak } \\
(\mathrm{nm})\end{array}$ & $\begin{array}{c}\text { Defect peak } \\
(\mathrm{nm})\end{array}$ & $I_{\text {Main }} / I_{\text {Defect }}$ & $I_{2 \mathrm{LO}} / I_{1 \mathrm{LO}}$ \\
\hline 160 & $3 \cdot 5$ & 480 & 496 & 668 & $14 \cdot 37$ & $0 \cdot 69$ \\
$=$ & $7 \cdot 0$ & 480 & 496 & 668 & $1 \cdot 77$ & $0 \cdot 71$ \\
$=$ & 24 & 485 & 519 & 690 & $0 \cdot 38$ & $1 \cdot 03$ \\
200 & $3 \cdot 5$ & 485 & 510 & 690 & $2 \cdot 60$ & $0 \cdot 70$ \\
$=$ & $7 \cdot 0$ & 485 & 512 & 690 & $1 \cdot 10$ & $1 \cdot 32$ \\
$=$ & 24 & 485 & 512 & 690 & $1 \cdot 00$ & $1 \cdot 20$ \\
\hline
\end{tabular}

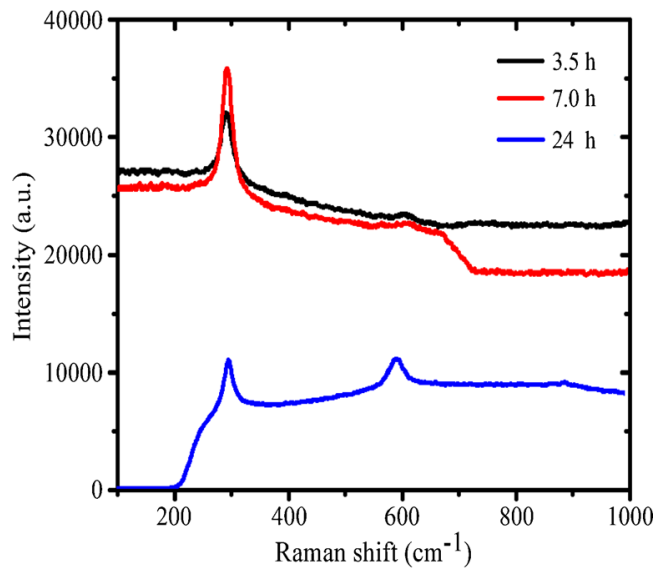

(A)

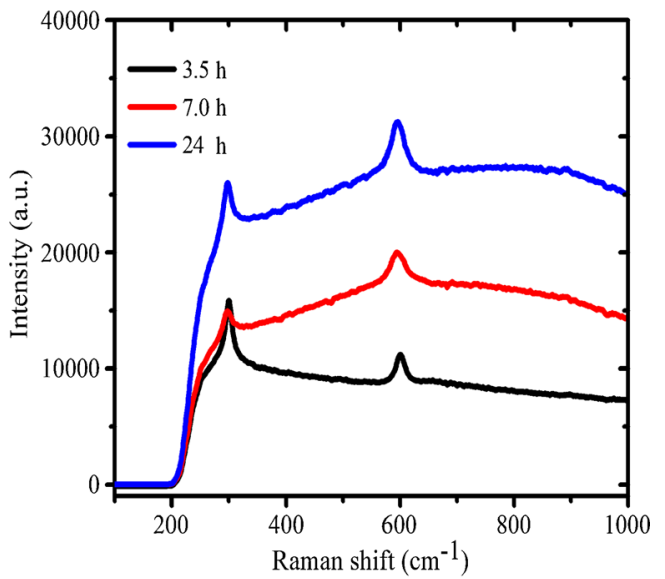

(B)

Figure 8. Raman spectra of CdS nanowires prepared (A) at $160{ }^{\circ} \mathrm{C}$ and (B) at $200{ }^{\circ} \mathrm{C}$ for various times.

the intensity ratio of the phonon overtone to the fundamental $\left(I_{2 \mathrm{LO}} / I_{1 \mathrm{LO}}\right)$ (Mahdi et al 2012d). The CdS NWs prepared at $160{ }^{\circ} \mathrm{C}$ for $24 \mathrm{~h}$ show higher $\left(I_{2 \mathrm{LO}} / I_{1 \mathrm{LO}}\right)$ intensity ratios than the samples prepared for 3.5 and $7 \mathrm{~h}$. On the other hand, the NWs prepared at $200{ }^{\circ} \mathrm{C}$ for $7 \mathrm{~h}$ have the highest $\left(I_{2 \mathrm{LO}} / I_{1 \mathrm{LO}}\right)$ intensity ratio (table 2$)$. NWs with high $\left(I_{2 \mathrm{LO}} / I_{1 \mathrm{LO}}\right)$ intensity ratios exhibit strong exciton-LO phonons because of phonon confinement in the transverse directions and the transfer of elementary excitation (carriers, excitons and phonons) to the longitudinal direction (Cao et al 2007). These single-crystal
CdS NWs possess high optical properties and are promising building blocks for photonic devices (Yan et al 2009).

\section{Conclusions}

CdS NWs/nanorods were prepared by the solvothermal method at 160 and $200{ }^{\circ} \mathrm{C}$ for $3 \cdot 5,7$ and $24 \mathrm{~h}$ and using en as a solvent. The dimensions of the grown CdS NWs are found to depend on the reaction temperature and duration. Analysis of the diameter distribution of the CdS NWs grown at 160 and $200{ }^{\circ} \mathrm{C}$ shows that the reaction duration does not significantly affect the wire diameter. A three-armed CdS nanorod structure frequently appears in all the samples prepared at 160 and $200{ }^{\circ} \mathrm{C}$. Appearing three-armed CdS nanorod structure can be attributed to the CdS nanoparticles in the solution, which acts as nuclei for the growth of this structure. The CdS NWs grown at $200{ }^{\circ} \mathrm{C}$ for $3 \cdot 5,7$ and $24 \mathrm{~h}$ are longer than those prepared at $160{ }^{\circ} \mathrm{C}$. The crystalline structure of all grown CdS NWs is wurtzite, and the NW/nanorod growth direction is along the $\langle 001\rangle$ plane. The NW diameters estimated from the XRD results are almost identical to those calculated from the TEM images, thus the XRD method can be used efficiently to calculate the diameter of the NWs. Sharp absorption peaks of the CdS NWs with blueshifts in the absorption edge are observed in all the prepared samples. The optical band gap of the NWs prepared at $160{ }^{\circ} \mathrm{C}$ decreases from 2.58 to $2.55 \mathrm{eV}$ with increased reaction duration from 3.5 to $24 \mathrm{~h}$. However, the band gaps of the samples grown at $200{ }^{\circ} \mathrm{C}$ are unaffected. The PL emission spectra of the CdS NWs prepared at 160 and $200{ }^{\circ} \mathrm{C}$ for $3.5 \mathrm{~h}$ show a sharp green emission. The ratios of the band-band emission to the defect intensity for the samples prepared at $200{ }^{\circ} \mathrm{C}$ are lower than those for the samples prepared at $160{ }^{\circ} \mathrm{C}$. Raman results show that the optical properties of the nanostructures are enhanced with increased reaction duration for all prepared CdS NWs.

\section{Acknowledgements}

The authors gratefully acknowledge the support of the Research University (RU) grant and the University Sains Malaysia. 


\section{References}

Ahmad-Bitar R N 2000 Renew. Energ. 19579

Arguello C A, Rousseau D L and Porto S P S 1969 Phys. Rev. 181 1351

Cao B L, Jiang Y, Wang C, Wang W H, Wang L Z, Niu M, Zhang W J, Li Y Q and Lee S T 2007 Adv. Funct. Mater. 171501

Chen S W and Wu J M 2011 Acta Mater. 59841

Chen M, Xie Y, Lu J, Xiong Y, Zhang S, Qian Y and Liu X 2002 J. Mater. Chem. 12748

Choi Y J, Park K S and Park J G 2010 Nanotechnol. 21509901

Dalvand P and Mohammadi M R 2011 J. Nanopart. Res. 133011

Dalvand P, Mohammadi M R and Fray D J 2011 Matter. Lett. 65 1291

Datta A, Chavan P G, Sheini F J, More M A, Joag D S and Patra A 2009 Cryst. Growth Des. 94157

Jang J S, Joshi U A and Lee J S 2007 J. Phys. Chem. C 11113280

Kar S and Chaudhuri S 2006 J. Phys. Chem. B 1104542

Kar S, Santra S and Heinrich H 2008 J. Phys. Chem. C 112 4036

Li Q H, Gao T and Wang T H 2005 Appl. Phys. Lett. 86193109

Li L, Wu P, Fang X, Zhai T, Dai L, Liao M, Koide Y, Wang H Q, Bando Y and Golberg D 2010 Adv. Mater. 223161

Ma R M, Wei X L, Dai L, Huo H D and Qin G G 2007 Nanotechnol. 18205605

Mahdi M A, Hassan J J, Ng S S and Hassan Z 2012a Physica. E 44 1716

Mahdi M A, Hassan Z, Ng S S, Hassan J J and Mohd Bakhori S K 2012b Thin Solid Films 5203477

Mahdi M A, Hassan J J, Ng S S and Hassan Z 2012c J. Cryst. Growth 35943

Mahdi M A, Asmiet Ramzy, Hassan Z, Ng S S, Hassan J J and Kasim S K 2012d Chalcogen. Letts. 919

Mondal S P, Dhar A and Ray S K 2007a Mat. Sci. Semicon. Proc. 10185
Mondal S P, Das K, Dhar A and Ray S K 2007b Nanotechnol. 18 095606

Nien Y T, Chen P W and Chen I J 2008 J. Alloys Compd. 462398

Nirmala Jothi N S, Chisty P D, Baby Suganthi A R, Ramalingam G and Sagayaraj P 2011 J. Crys. Growth 316126

Owens F J and Poole C P 2008 The physics and chemistry of nanosolids (Hoboken, New Jersey, USA: John Wiley \& Sons Inc.)

Pan A L, Liu R B, Yang Q, Zhu Y C, Yang G Z, Zou B S and Chen K Q 2005 J. Phys. Chem. B 10924268

Phuruangrat A, Thongtoem T and Thongtoem S 2009 Mater. Lett. 631538

Phuruangrat A, Thongtem T and Thongten S 2010 Chalcogen. Letts. 7605

Qingqing W, Gang X and Gaorong H 2005 J. Solid State Chem. 178 2680

Rai P, Song H M, Kim Y S, Song M K, Oh P R, Yoon J M and Yu Y T 2012 Mater. Lett. 6890

Sadhu S, Chowdhury P S and Patra A 2008 J. Lumin. 1281235

Thupakula U, Jena A, Khan A H, Dalui A and Acharya S 2012 J. Nanopart. Res. 14701

Tsai C T, Chuu D S, Chen G L and Yang S L 1996 J. Appl. Phys. 799105

Wang Y W, Meng G W, Zhang L D, Liang C H and Zhang J 2002 Chem. Mater. 141773

Wang X, Liu W, Yang H, Li X, Li N, Shi R, Zhao H and Yu J 2011 Acta Mater. 591291

Xi Y, Hu C, Zheng C, Zhang H, Yang R and Tian Y 2010 Mater. Res. Bull. 451476

Xu D, Liu Z, Liang J and Qian Y 2005 J. Phys. Chem. B 10914344

Yan S, Sun L, Qu P, Huang N, Song Y and Xiao Z 2009 J. Solid State Chem. 1822941

Yingkai L, Xiangping Z, Dedong H and Hui W 2006 J. Mater. Sci. 416492

Zhou J, Zhao G, Yang J and Hano G 2011 J. Alloys Compd. 509 6731 